\title{
Teacher Training Systems in Three Countries (Finland, France and Morocco): Comparative Study of Professionalization Models and Their Challenges
}

\author{
Moncef Barzane ${ }^{(凶)}$, Soukaina Essalih, Mustapha Ourahay and Salaheddine Khzami \\ Caddi ayyad, ENS, Pedagogy and didactic, Massira3, Marrakesh, Morocco \\ barzane14 @gmail.com
}

\section{ABSTRACT}

Teacher training is still a problematic subject in projects to reform education systems. Through the quest for quality education, it has experienced major changes in different contexts in connection with the process of "professionalization". The different mechanisms of this training must allow teachers to acquire disciplinary knowledge and develop skills in order to be able to build quality teaching and learning. In addition, there seems to be a relationship between the effectiveness of the teacher and the level of quality of his training. Study results have revealed particularly poor performance levels among students whose teachers are characterized by "poor quality education and uncontrolled knowledge in the subjects they teach" (Bidjang, S. G. 2005). In other words: the effectiveness of teaching depends at least to a significant extent on what "the teachers bring". Morocco in the last reform took up professionalization and universitarization as new approaches to teacher training. However, despite the progress recorded in terms of educational training provision, the reform has not been accompanied through strategic measures. Training in Morocco appears to suffer from a number of shortcomings. The objective of the study is to discover, thanks to the comparison of three training systems (Finland, France and Morocco) if there are characteristics which would allow us to understand the relative "advantages" of one system compared to another, and to what extent such a comparison would help us improve Morocco's. The country in question are considered to have the best performing education systems globally. This involves carrying out a comparative documentary study, that is to say analysing existing documents on teacher training systems by comparing them in the mentioned context.

Keywords: education, professionalization, knowledge and skills, approaches, effectiveness of teaching

Cite this article as: Barzane, M., Essalih, S., Ourahay, M., \& Khzami, S. (2020). Teacher Training Systems in Three Countries (Finland, France and Morocco): Comparative Study of Professionalization Models and Their Challenges. International Journal of Higher Education Pedagogies, 1(1), 23-29. https://doi.org/10.33422/ijhep.v1i1.2

\section{Introduction}

Finland, with a population of 5.359 .538 (2010 estimate), a Scandinavian country in the Baltic Sea coast. There are two main language of Finland, Finnish and Swedish. According to data from the year $2010 \% 11.9$ of public expenditure in education is. Schooling rate is close to $\% 100$ at compulsory education and preschool, basic education, secondary education is completely free (Ekinci and Öter, 2010). Education is responsibility of the Ministry of Education in Finland. National Board of Education with the Ministry are working to develop training objectives, contents and methods for the secondary and adult education. In addition each of the six provinces of Finland have to Ministry of Education and Culture dealing with these issues (Eurydice, 2011)

Basic education includes for 9 years process to Finland (7-16 age) and almost all children must complete this compulsory education. The school year begins mid August and continues to early June, contains a total of 190 days. The National Curriculum includes goals and 
assessment criteria set by the National Board of Education. All schools and local governments create curriculum and regulations accordance with local scopes. Teachers choose their own methods and they are freedom to determine their own educational materials (Eurydice, 2011).

The National Curriculum includes goals and assessment criteria set by the National Board of Education. All schools and local governments create curriculum and regulations accordance with local scopes. Teachers choose their own methods and they are freedom to determine their own educational materials (Eurydice, 2011). Compulsory core subjects to basic education; Finnish or Swedish the main language and literature, second national language, foreign languages, environmental studies, health education, science of religion and morality, history, social sciences, mathematics, physics, chemistry, biology, geography, physical education, music, visual arts, crafts, home economics, guidance courses. Teachers develop evaluation objectives written into the curriculum. Each student has a report at least once. In addition, at least once during the school year may be an intermediate report. Students who successfully complete 9 years of comprehensive school life are given a certificate (Eurydice, 2011). Students who successfully complete mandatory training is suitable for general and vocational education.

At the organizational level in Morocco's system, it should be noted the increased involvement of universities with the FUE (18 accreditations for 2012). (Decision of the Minister of National Education concerning the terms and conditions of access to CRMEF. 2012). In addition, initial training is provided in most cases by the ENS, which now depend on the universities. The second phase, called "qualifying training", is provided by the 15 new CRMEFs, which have replaced the old CPRs and CFIs. According to the creation decree, a CRMEF is an "institution of higher education which does not depend on the university", but is "under the supervision of the government authority responsible for school education". The same text aligns the distribution of the centers on the geographical map of the academies and sets out a set of missions entrusted to the CRMEF, such as: the qualification of teachers; preparation for the competitive examination; training of directors and support staff; the organization of continuing training sessions; scientific and educational research; documentary production and the development of reform project proposals in terms of curricula and training. (Decision of the Minister of National Education concerning the seats and annexes of the CRMEF. 2012).

Since the creation of the IUFM in 1991 and until now, the initial training of teachers secondary school (PLC2 )'s mission is to best support the construction of professional skills expected by the institution (official texts 1997, 2007). Founded on the work-study program, this training remains largely inspired by the model of the "practitioner reflective "(Schön, 1983) capable of analyzing its own practices, of building strategies by relying on plural knowledge, to adapt to new situations, to justify choice to eventually become an autonomous and responsible actor capable of fulfilling efficient the mission entrusted to it.

Teacher training is still a problematic subject in projects to reform education systems. Through the quest for quality education, it has experienced major changes in different contexts in connection with the process of "professionalization". The different mechanisms of this training must allow teachers to acquire disciplinary knowledge and develop skills in order to be able to build quality teaching and learning. Morocco in the last reform took up professionalization and universitalisation as new approaches to teacher training. However, despite the progress made in the area of educational training, the reform has not been accompanied by strategic measures. 
Training in Morocco appears to suffer from a number of shortcomings. In this regard, we must emphasize that both learning the trade and personal growth, access to the position, the quality of the tasks assigned, acculturation to the environment, integration into the school team and social and professional recognition are major issues during professional integration (Bidjang, S. G., Gauthier, C., Mellouki, M. et Desbiens, J.-F. (2005)). Therefore, it can be said that there is still room for improvement in some programs to better meet the diverse needs of beginning teachers. The comparison of training programs cannot lead to a transposition of a model as a whole from one context to another, and this because of the specific contexts and issues that characterize them. Nevertheless, it is possible to identify improvements that could be made to the Moroccan teacher training program from the other models.

The objective of the study is to discover through the comparison of three training systems ( Finland, France and Morocco) if there are characteristics which would allow us to understand the relative "advantages" of a system compared to another, and to what extent such a comparison would help us improve Morocco's program.

\section{Methodology}

More specifically, it involves analyzing the implementation of professionalization in the Three systems, the nature and organization of initial training programs, as well as the issues that characterize them.

This is a qualitative type of research, which includes a descriptive aim, through which one must seek to identify specific elements and establish relationships between them. Various elements seemed to us to be of decisive importance for the understanding of the training models for secondary teachers practiced in Finland: the university nature of the training and the place given to practitioner expertise, the nature and organization of the partnership. training establishments / institution as well as the supervision and support system for teachertrainees. In this reflexive model, the practice of teaching in responsibility is the central element of the training, from and around which the rest of the training actions are articulated, in particular through the preparation, the support, the exploitation and the systematic analysis of professional experiences and trainees' experiences.

In the case of Finland, the simultaneous model, future teachers follow professional and academic courses at the same time, throughout their training. The length of programs in this model is difficult to determine, but most can be three or four years in a bachelor's degree program (Crocker \& Dibbon, 2008). New teachers will have to have 16 years of schooling, including three years at university. They will then have to complete two years of probation in a school, probation evaluated by the administration, in order to obtain their permanent teaching certificate.).

\section{Results}

\subsection{Finland Context}

The compulsory subjects in general upper secondary education; the main language and literature, second national language, foreign languages, mathematics and natural science studies, humanities and social sciences, curriculum includes courses on convicts. Vocational secondary education includes apprenticeship training and other competence training (cultural, social science competency training) outside of school-based education (Eurydice, 2011). Higher education, technical schools and universities are divided into two. Universities emphasize scientific research and teaching; but technical schools is based on more practice- 
oriented vocational training.( Ekinci and Öter, 2010, s.18). Finland is used as a criterion of eligibility for higher education in the university entrance exam. University placements are done by looking at university entrance exam, institutes, faculties, or as a result of entrance examination organized by the department and upper secondary school leaving certificate. (Ekinci and Öter, 2010, s.19) According to the Universities very low or very high academic levels is possible to. A lower level or license degree are 180 AKTS and completed in 3 years. A high level or license degree are 120 AKTS and completed in 2 years (Eurydice, 2011).

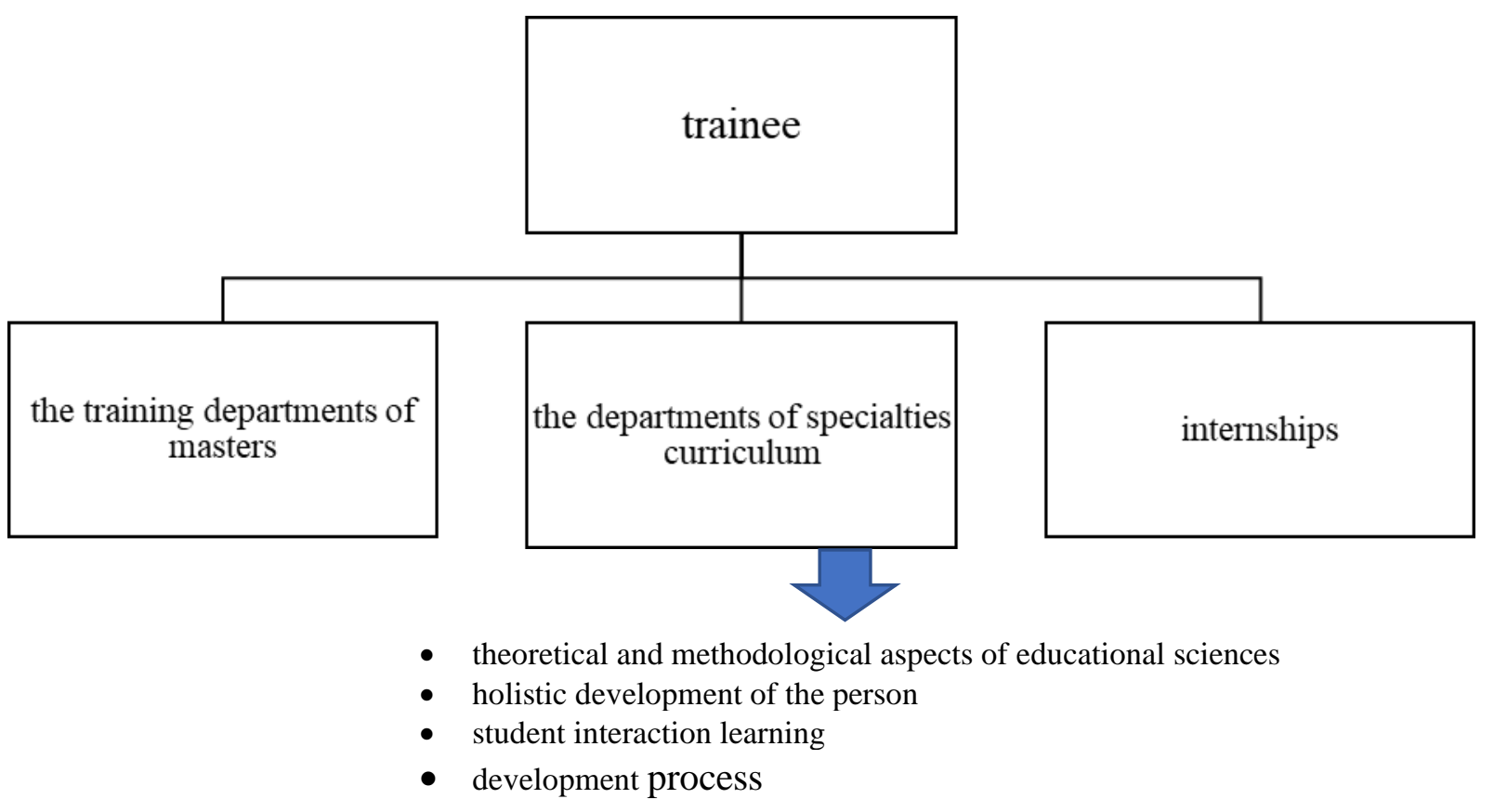

Figure 1. General Composition of teacher training system in Finland

\subsection{French context}

Trainee teachers are invited to articulate knowledge for and to teach, reflection on and in action, the consistency sought in the training plans carried out by the various actors (trainers, trainees, inspectorates, heads of establishments) in the regulatory and evaluation bodies set up by the institution. It also supported the reflections carried out in the context of the training of trainers, a space where a number of lively questions related to the present and future challenges of the professionalization of teachers are addressed. (Altet, 2000) . In this IUFM, the program places professional practice at the heart of training. This practice is understood as an activity within the classroom, the school, the education system and in conjunction with partners. Considered a full member of the educational team, the trainee provides a teaching service for which he is fully responsible. This "work-study" training requires complementarity between the different actors, in the establishment where the internship in responsibility takes place and at the IUFM. At by way of illustration, the three systems presented below are designed by the training institution in a very articulate manner. 


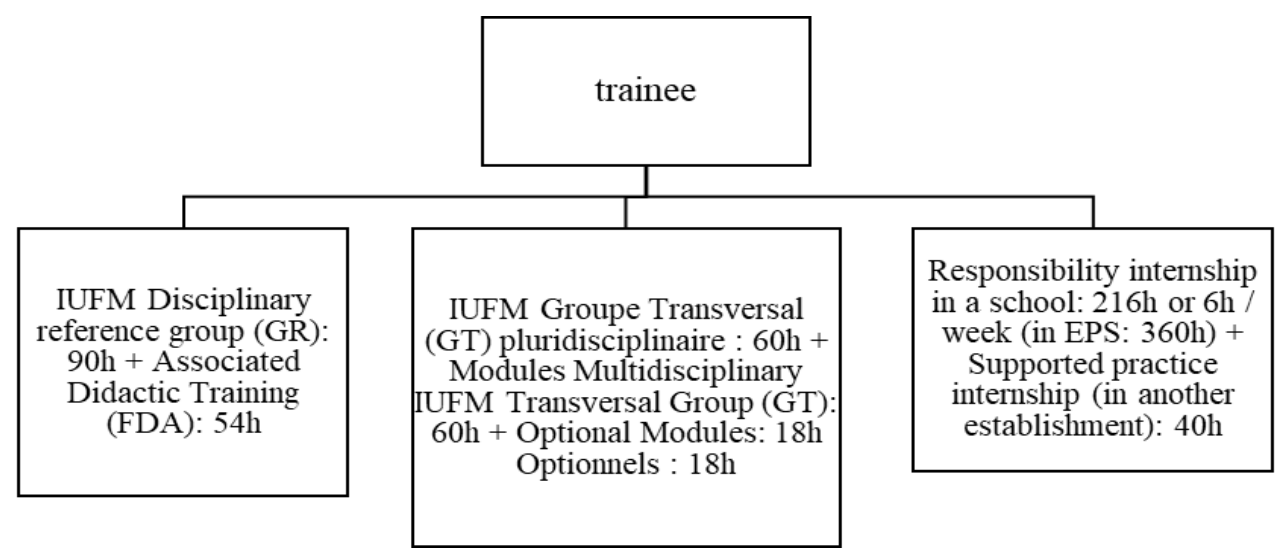

Figure 2. Organization of teacher training system in France

\subsection{Morocco's context}

Although we have detected both major similarities and differences, this issue still needs to be further explored to continue improving teacher education. From the information gathered on the training systems of the countries in question, we suggest more open and flexible systems which do not forget the importance of teacher training, the status of the teacher, the selection of the teacher or the role of the teacher as an active member of the system.

The different educational outcomes and models pose problems of quality, performance and relevance of the teacher at the forefront of our modern societies.

In the case of Finland, the simultaneous model, future teachers follow professional and academic courses at the same time, throughout their training. The length of programs in this model is difficult to determine, but most can be three or four years in a bachelor's degree program (Crocker \& Dibbon, 2008). New teachers will have to have 16 years of schooling, including three years at university. They will then have to complete two years of probation in a school, probation evaluated by the administration, in order to obtain their permanent teaching certificate.

\section{Discussion}

Regarding the organization of practical training at the University of Finland, students complete one internship per year, starting from the first year of training, or 4 internships at the University of Finland. However, internships at the University account for a total of 945 hours of training, or $17.5 \%$ of the total number of credits in the program. Students in initial training must therefore participate in all kinds of assessment activities, such as written exams, oral presentations, work carried out in class or at home, etc. Of course, they must also participate in internships, which are also part of the evaluation activities. Ultimately, we can retain from previous analyzes that the programs in Finland are strongly focused on didactics, with a significant part of pedagogy and training in the practice environment. 


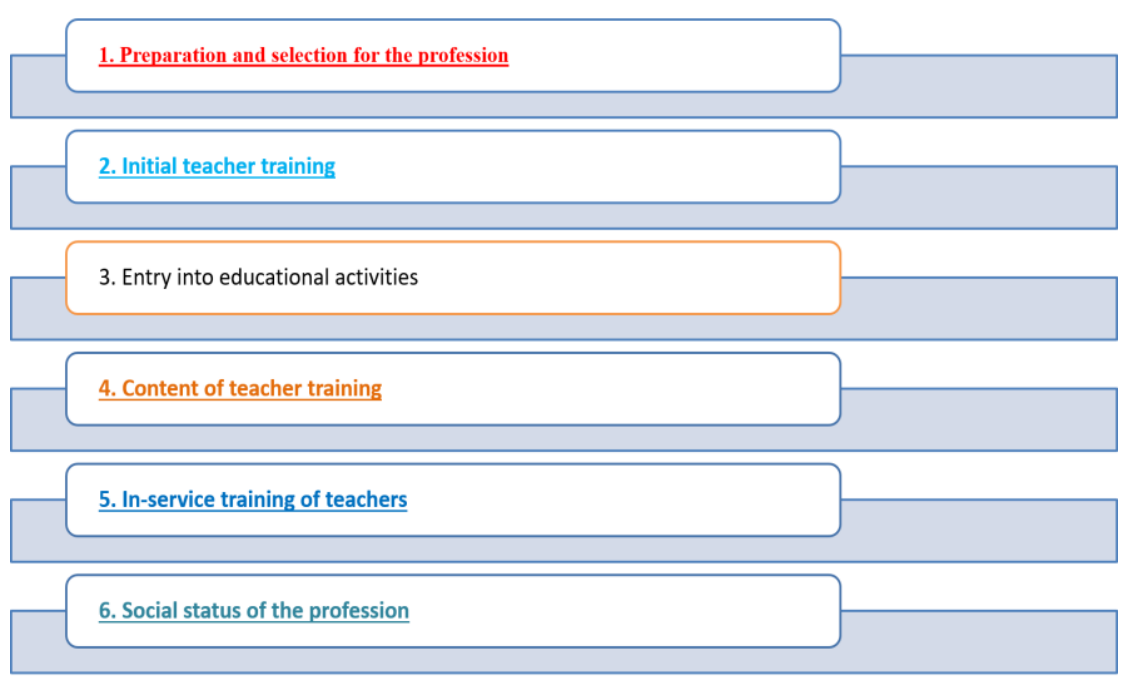

Figure 3. General criteria to analyse the teacher training system studied

\section{Conclusion}

Our political, economic and social responses should help place teachers and teacher training in a positive position, recognizing its primary role in educational outcomes and, where possible, building on the experiences of others in order to avoid making the same mistakes. The comparison of training programs cannot lead to a transposition of a model as a whole from one context to another, and this because of the specific contexts and issues that characterize them.

The different educational outcomes and models pose problems of quality, performance and relevance of the teacher at the forefront of our modern societies. emphasizing that both learning the trade and personal growth, access to the position, the quality of the tasks assigned, acculturation to the environment, integration into the school team and social and professional recognition are major issues during professional integration.

it is possible to identify improvements that could be made to the Moroccan teacher training program from the other models.

\section{References}

Altet, M. (2000). Analysis of practices, a professional training approach ?, Research and Training, 35, 25-41

Bidjang, S. G. (2005). Description of the level of mastery of professional skills of trainees graduating in teaching in Quebec. Doctoral thesis. Quebec: Laval University.

Bidjang, S. G., Gauthier, C., Mellouki, M. et Desbiens, J.-F. (2005). Les finissants en enseignement sont-ils compétents? Une enquête québécoise. Québec: PUL . https://doi.org/10.7202/018976ar

Carnegie Forum on Education and the Economy. Task Force on Teaching as a Profession. (1986). A nation prepared: teachers for the 21st century. Washington: Carnegie Forum on Education and the Economy.

Crocker, R. \& Dibbon, D. (2008). Teacher Education in Canada. A Baseline Study. Canada: Society for the Advancement of Excellence in Education Aho, E., Pitkänen, K., \& 
Sahlberg, P. (2006). Policy Development and Reform Principles of Basic and Secondary Education in Finland since 1968. Education Working Paper Series. The World Bank (2).

Decision of the Minister of National Education concerning the seats and annexes of the CRMEF, n 12.1866, March 15, 2012, Rabat.

Decision of the Minister of National Education concerning the terms and conditions of access to CRMEF, preschool and primary cycle, No. 12.2199, college cycle; No. 12.2201; qualifying cycle, n 12.2200, May 21, 2012, Rabat.

Ekinci, Ö. and Öter, Ö. (2010). Education and Teacher Training System in Finland, Study Visit Report. Çobanolu, R. and Kasapolu, K. (2010). Reasons for the Finnish success in PISA and hows, Hacettepe University, Journal of Education, 39, 121-131.

Eurydice. National system overview on education system in Europe and ongoing reforms: Finland, November 2011, 9 p.191 / 5000.

Official Bulletin n 1, January 4, 2007. Specifications for the training of teachers in University Institute for Teachers' Training

Official Bulletin n 22, May 29, 1997. Mission of the teacher working in college, high school general and technological education or vocational high school.

Schön, D.A. (1983). The reflective practitioner. New York : Basic Book. 